\title{
A NETWORKED QUESTION-POSING AND PEER ASSESSMENT LEARNING SYSTEM: A COGNITIVE ENHANCING TOOL*
}

\author{
FU-YUN YU \\ National Cheng-Kung University, Taiwan \\ YU-HSIN LIU \\ National Chi-Nan University, Taiwan \\ TAK-WAI CHAN \\ National Central University, Taiwan
}

\begin{abstract}
In light of constructivism and cognitive psychology, a networked learning system enabling students to pose questions that are assessed, viewed, and answered via peers, is described in the article. A study examining the system's learning potentials and design features was conducted with 52 sixth graders. Overall, students rated favorably on the system's interface design and potentials in promoting their cognitive capability in the content domain. Questionnaires, open-ended questions, and classroom observations further revealed that via playing the roles of question-posers, assessors, viewers, adapters, and answers at various points during the process, students seemed to actively engage in the learning process by constructing and re-constructing their own interpretations of the world of information around them, which was facilitative for understanding and cognitive development. Suggestions for future studies were offered.
\end{abstract}

*This project is funded by the Ministry of Education of the Republic of China under a four-year project (January 2000 to December 2003): Learning Technology, Active Social Learning and its Applications from Taiwan to the World," sub-project: "A Synchronous Competitive Educational Game" (Project No. 89-H-FA07-1-4). 


\section{INTRODUCTION}

In light of many of the distinct features associated with computers-for instance, multimedia appealingness, immense storage space, high processing speed, learner control, instant and personalized responses to learner actions, numbercrunching, and multiple-branching capabilities - computers present themselves as a promising instructional and learning device since its advent $[1,2]$. Specifically, researchers in educational technology advocate the idea of using computers as a tool of student performance elicitation and assessment. Application of computer technology in this area has demonstrated its potentials to carry out such tasks efficiently, effectively, and affectively [2-4]. For instance, by dynamically adjusting the difficulty levels of test items based on users' general proficiency and responses to the posted questions, computerized adaptive testing produces significant time-savings over conventional paper-and-pencil assessment procedures without compromising validity and reliability [3-5]. Besides, the "learner-control of pace" and "individualization" aspects of computers provide a private, patient, and affective climate. This helps to provide an un-intimidating environment for unlimited numbers of drill-and-practice and test-taking sessions, and is especially useful for slower learners [2]. Moreover, computers' high-speed processing capability and instant feedback to students' input not only alleviate instructors' routine work to evaluate, score, analyze, and record student performance, but act as a positive reinforcer for students [3].

Currently, as multimedia and Internet technologies converge, Web-based performance elicitation and assessment learning systems are getting popularity [6-8]. There are several extra-advantages to have learning activities conducted via Internet. First and foremost, being Web-based means that the system is not tied to particular computer architecture or bound to a specific operation system. In other words, Web-based performance elicitation and assessment is less deviceindependent $[9,10]$. Secondly, updating, maintenance, and management of databases are easy as materials and users' database are stored at the server site [11].

Seeing Web's inviting features and its potentials for interactivity and learning, an online domain-independent learning system, called JOYCE, which adopts a "monopoly" type of board-game format and allows students to compete answering multiple-choice questions with another party, was devised in an attempt to actively engage students in repetitive drill-and-practice exercises [12]. Despite JOYCE's success at being able to provide a satisfactory and motivating learning experience compatible with student learning mode preferences [13], several difficulties surmounted the system for its widespread diffusion and classroom usage. Amidst, lack of sufficient test banks affected most of all.

In the case of developing a domain independent performance elicitation system, the heaviest burden, after the design and development of system architecture, lies in building up the test banks for different subject matters from scratch or obtaining permission from different publishers to import their established item banks, which 
often adopted different database structures. Faced with such obstacles, the research team decided to develop a sub-learning system, named Question-Posing and Peer Assessment learning system (hereinafter named QPPA), to supplement JOYCE. QPPA allows rapid, anonymous, and simultaneous question-posing, peer assessing, question-viewing, and drill-and-practice learning activities for various subject matters for all levels of schooling.

Though the face value of QPPA may seem to be easing the item bank construction work confronting JOYCE, a more important rationale directing the project gleaned from constructivism and cognitive psychology. Constructivism considers engaging students in meaningful experiences as the essence of learning. It emphasizes that learners create their own interpretations of the world of information around them. The goal of instruction, from the perspectives of constructivists, is to create situations that enhance learners' interpretation and reflection for their own understanding and cognitive development [2, 14, 15]. Contrasting with traditional classrooms where students answer questions generally provided by teachers, enabling students to contribute to questions tends to encourage more active manipulation of information and knowledge on the learners' part [16].

Researchers in cognitive psychology, on the other hand, have long held that if information is to be retained and related to information already stored in memory, the learner must engage in some sorts of deep-processing, such as rehearsal, organization elaboration, etc., to help cognitive structuring or re-construction $[17,18]$. Elaboration like those involved in question-posing and assessing others' works may very well help learners comprehend and learn instructional materials. Specifically speaking, while generating multiple-choice questions via QPPA, students must construct a question-stem, the correct answer, and three alternatives. That is, students need to figure out which parts of the learning materials are important and worth testing, and which are not. Besides, they need to come up with the correct answer to the posted question if not given in the textbook. In other words, they need to go through the process of solving the question themselves. Furthermore, they need to ponder three distracters that can effectively discriminate those who did learn the materials and those who didn't. As for assessing peers' works, students need to assess the appropriateness of the stem, to test the correctness of the answer, and to gauge the appealingness of the three alternatives. To accomplish these tasks, students, no matter if they are playing the roles of question-posers or assessors, must constantly re-examine instructional materials so as to point out critical distinctive features or differences among closely related categories, to clarify relationships among pieces of information, and to compare newly acquired concepts to previously learned concepts; this involves the processes of rehearsal, organization, and elaboration. These, in view of cognitive psychology, should be beneficial to cognitive growth.

In the following section, an overview of the learning environment is introduced. As researchers suggested that engaging in the process of question-posing or peer assessing may be conducive to student cognitive growth [19-27], a study 
examining student perceptions toward the potentials of various functions and features in QPPA for the promotion of their cognitive growth is described next. Finally, results from the study and implications for future studies are offered.

\section{OVERVIEW OF THE QPPA LEARNING ENVIRONMENT}

In general, QPPA allows students to contribute and benefit from the process of generating questions, which are further assessed, viewed, and answered by their peers. With the support of Web technology, all of the tasks can be accomplished in a more instantaneous, anonymous, convenient, and environmentally friendly way. Specifically, with the support of Web technology, all questions composed by students can be assessed and viewed by their peers the very moment they are submitted. This reduces delay and paper expenditure, and avoids the hassles of collecting, shoveling, and re-disseminating questions among students as if they are done traditionally. Besides, without revealing whom the question posers and assessors are, Web-based question-posing is less inhibitive and objective assessment among peers can be more easily ensured [24].

Mainly, QPPA is comprised of four functions. They are question-posing, peer assessment, question-viewing, and drill-and-practice answering. Figure 1 presents the architecture of QPPA. Each of the functions is briefly described below.

\section{Question-Posing}

As shown in Figure 2, to contribute a question, students not only need to provide a question-stem and the correct answer to the posted question, but also need to come up with three plausible alternatives. In addition, students can give hints, cues, references, pictures/graphics, etc. to be used as learning aids while answering questions in JOYCE. All questions posed by students are kept in a temporary item bank database for peer assessment and question-viewing.

\section{Peer Assessment}

For the sake of quality control, the system installs a peer assessment mechanism to filter out defective items. To control the quality of each and every question, being assessed by at least five of their peers and with at least half of those being rated as acceptable were set as the criteria for transferring questions from the temporary item bank database to the formal item bank database. If questions fail to meet the pre-set criteria, they will be returned to the original question-posers for further refinement, revision, and re-submission.

To assess a question, students need to select an item from a "listing of questions for peer assessment" window. As shown in Figure 3, questions can be sequenced randomly, or based on the number of times they have been assessed, or the time they were posed, etc. Once deciding which item to assess, students can give 
COGNITIVE ENHANCING TOOL ／ 215

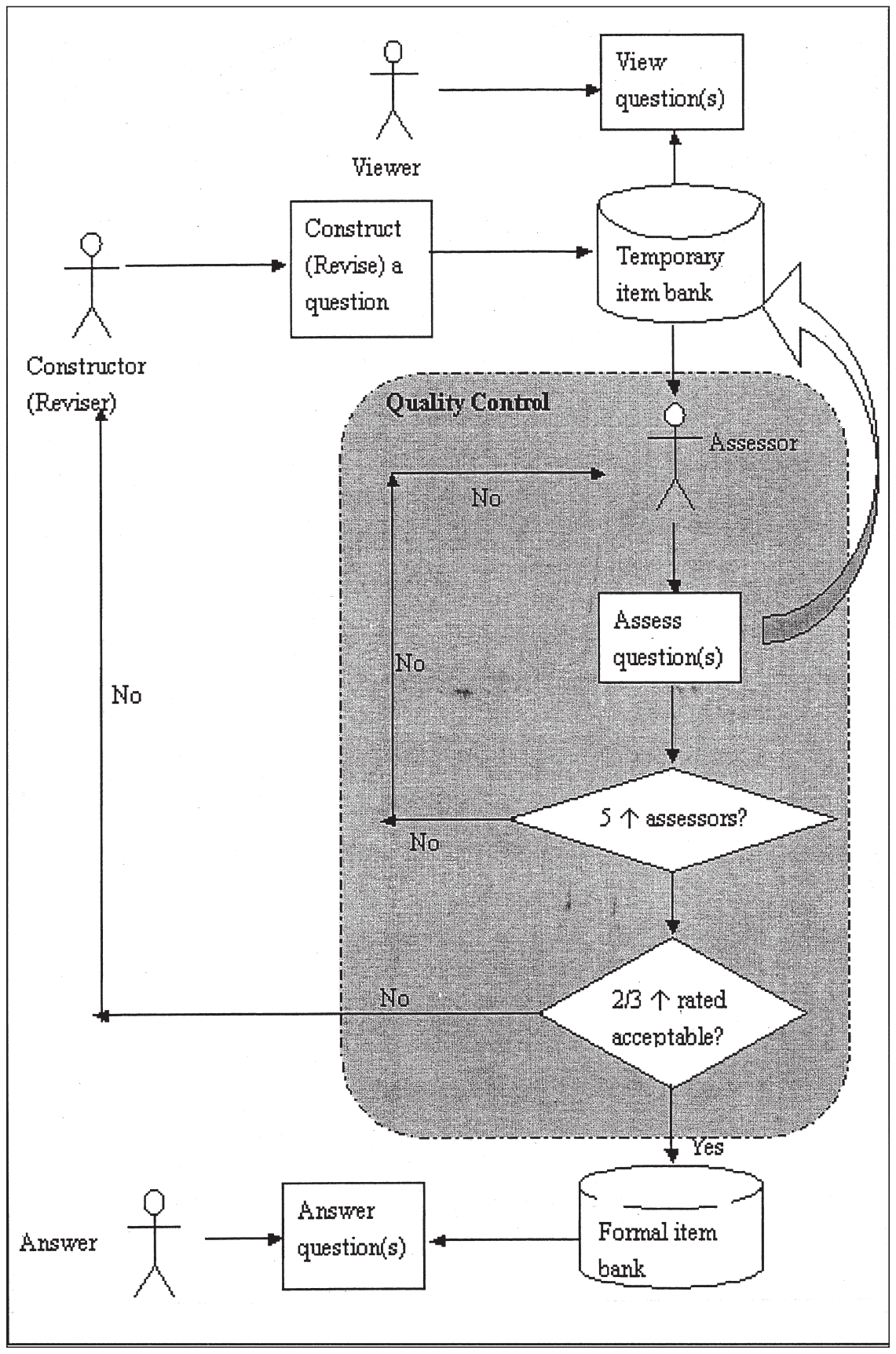

Figure 1. Architecture of the test construction with peer review mechanism. 


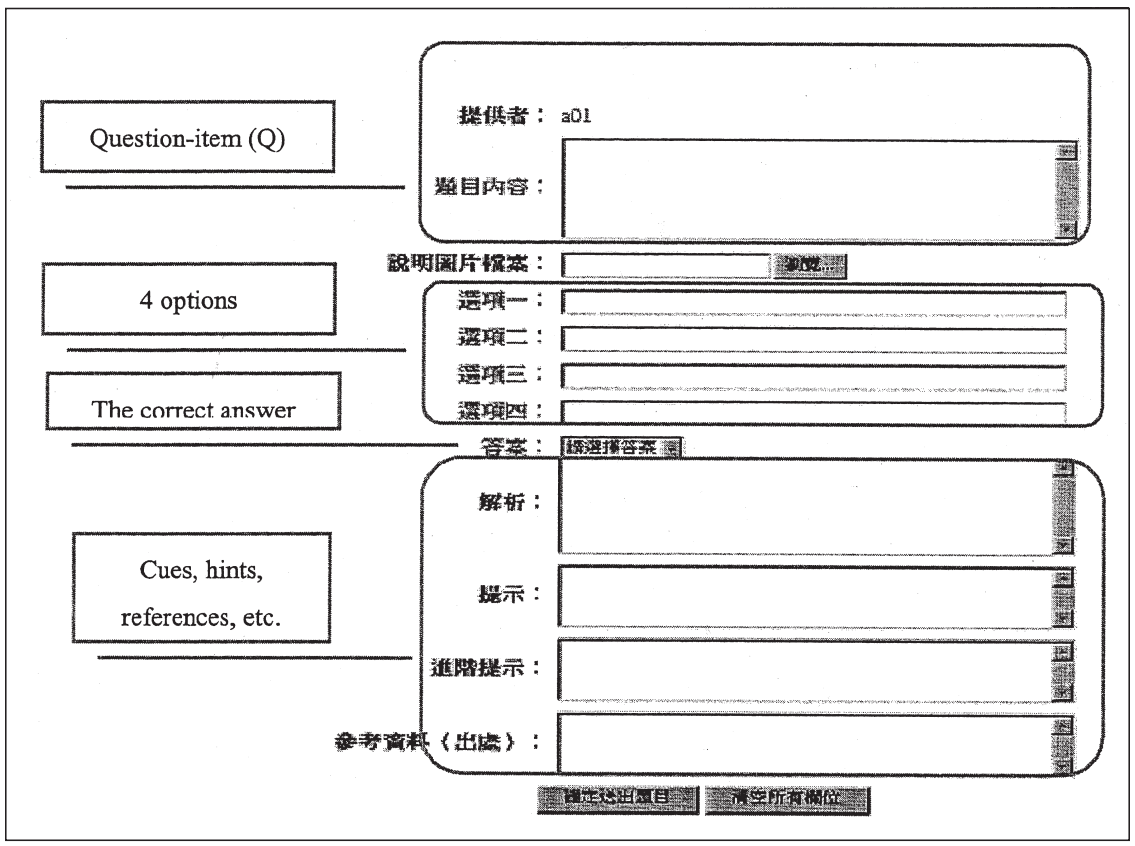

Figure 2. Question-posing function.

their feedback in an "assessment form." Some frequently made mistakes in multiple-choice question-posing - such as, question-stem is not presented clearly, question-stem is not in its simplest form, unnecessary repetition of wording in the options, more than one correct answer, distractors are not plausible enough, typos, etc. - are provided through a pull down menu in the assessment form (see Figure 4). This intends to, on one hand, act as a set of criteria for objective peer assessment, and on the other hand, a scaffolding device for the questionrevision phase. In addition to choosing pre-set comments, students can type in their comments and suggestions in the "feedback type-in-space." This mechanism intends to create dialogue and information exchange between question-posers and assessors, which in turns can further promote critical thinking and learning.

\section{Quesiton-Viewing}

Besides posing and assessing multiple-choice questions, QPPA sets up a question-viewing function to promote student learning by observing others' works. That is, by observing questions constructed by peers (the upper portion of Figure 5) and/or comments and suggestions given by assessors (the lower 


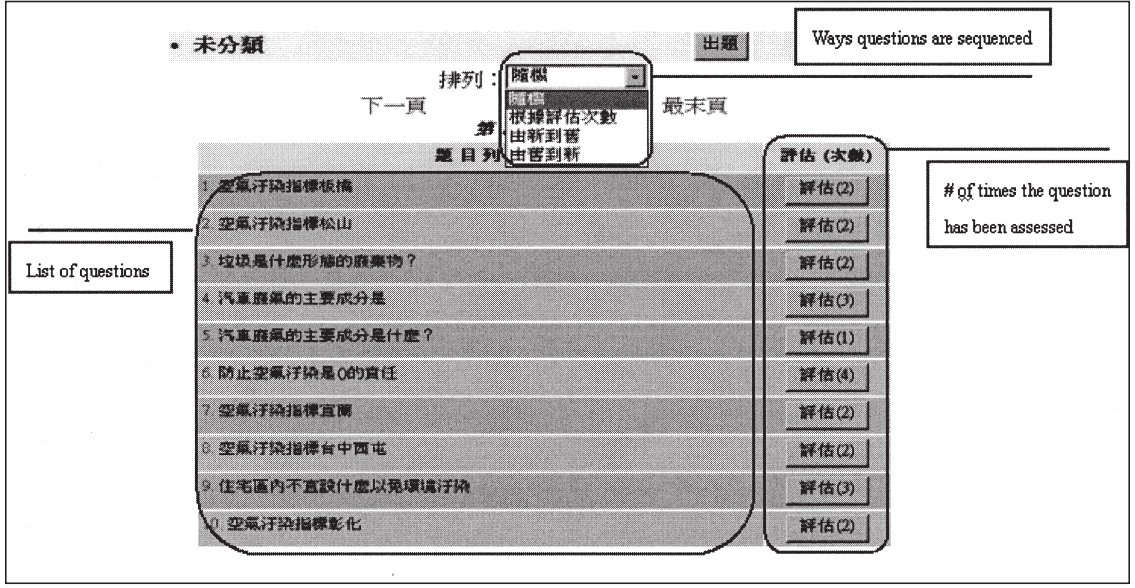

Figure 3. Listing of questions for peer assessment.

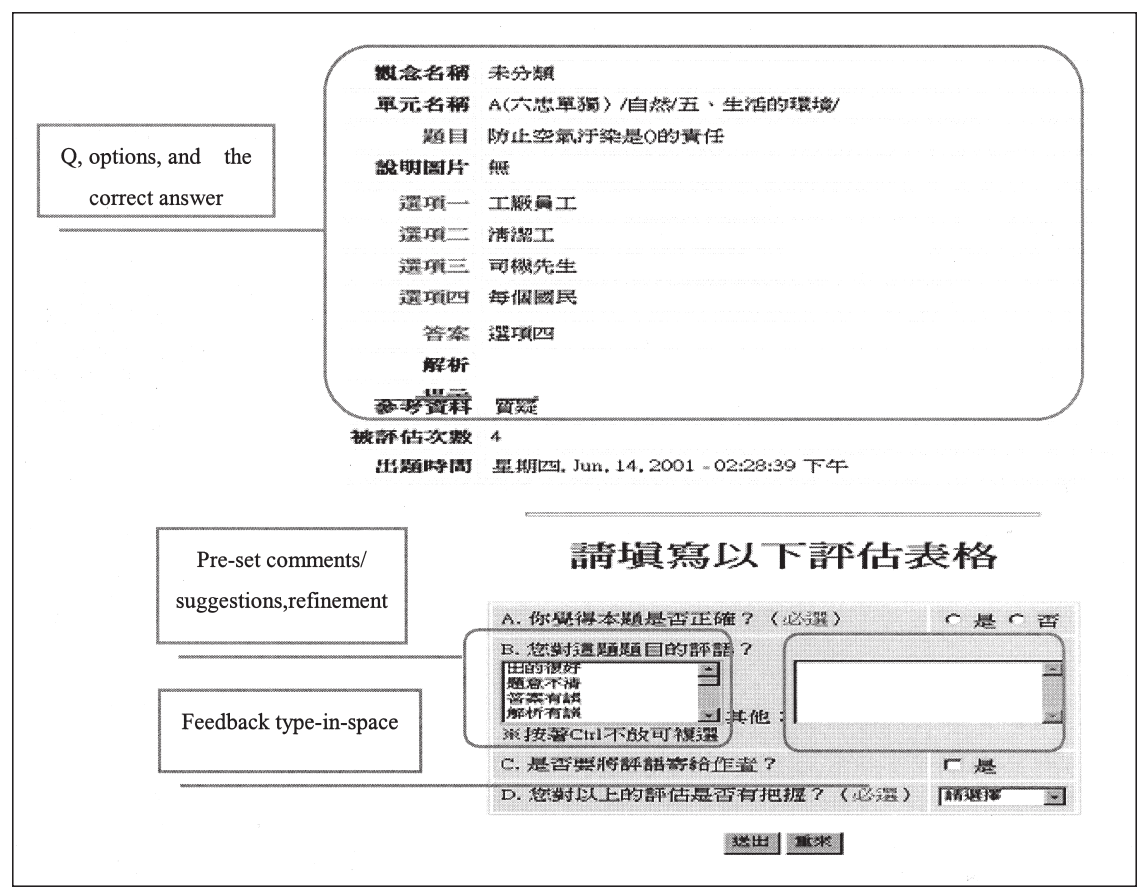

Figure 4. Peer assessment form. 


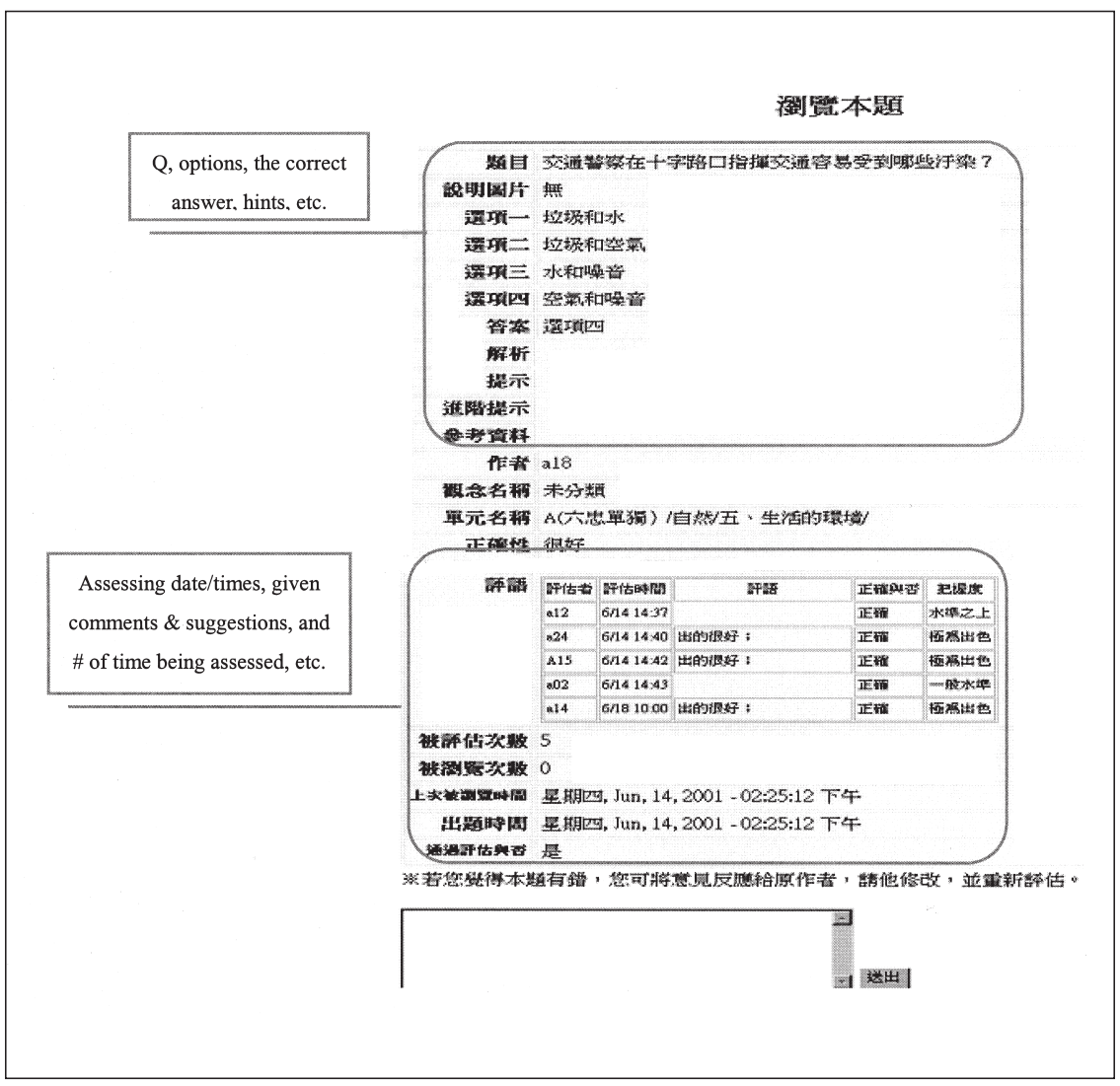

Figure 5. Question-viewing function.

portion of Figure 5), question-view function provides an observational learning environment for students to learn from each other.

\section{Drill-and-Practice Answering}

As mentioned previously, once questions pass through the peer assessment screening process, they are imported to the formal test bank database in QPPA. Students can choose the number of questions for drill-and-practice exercises. After answering, feedback as to how many questions were answered correctly and a review button - which permits further reviewing and learning - is provided. Finally, item analysis such as item difficulty and discrimination index will be done before questions can be further exported to JOYCE's test banks for synchronous question-answering games. 
Beside these four main functions, additional features - such as, Edu-dollars, online ranking lists, and statistics summaries on individual and class average performance - are included to increase QPPA's intrinsic motivational appealingness to users. Edu-dollars are virtual currencies. By participating in various functions in QPPA, students can accumulate different amounts of Edu-dollars. Six ranking lists are designed in QPPA. They are the top five players who accumulated the most Edu-dollars, the top five players who posed the most questions, the top five players who assessed the most questions, the top five players who answered the most questions correctly in drill-and-practice activity, the top five players whose questions were viewed most frequently, and the top five players who spent most time on-line.

\section{METHODOLOGY}

Overall, by engaging students in playing various roles as question-posers, assessors, observers, editors, adapters, and answers, QPPA intends to create a learning environment, which in view of constructivism and cognitive psychology would be conducive to cognitive growth. To examine the system's design features and functions for students' cognitive enhancement a study was conducted. Two classes of sixth-grade students $(N=52)$ from one primary school in the southern part of Taiwan participated in the study for six instructional sessions for three days in the computer lab of the participating school. In these sessions, students used the system as an extra-curricular learning activity for mathematics, natural science, and social science. Prior to interacting with the system, an orientation session on various features and operating procedures of QPPA was given to participating students.

A post-session self-report questionnaire was disseminated to students to be completed individually after the instructional sessions. The questionnaire consisted of three parts. The first part measured "Students' Confidence Toward QPPA's Potentials in Promoting Cognitive Ability." Hung's "Learning Experience Scale" was adopted and adapted to make the items better fit the learning situation and target population involved [28]. Seven Likert scale items were included and rated on a 5-part discrete scale, with corresponding verbal descriptions ranging from "strongly disagree" through "disagree," "no-opinion," and "agree" to "strongly agree." To counteract possible response-set tendencies, both positive and negative statements were included (Table 1). Based on the data collected from the study, the internal consistency reliability (coefficient alpha) for the scale was 0.60 . The second part of the questionnaire collected student opinions toward the usefulness and user-friendliness of the various functions and features in QPPA. The last part of the questionnaire was an openended question, which solicited student overall perceptions toward QPPA"In terms of learning, which part(s) of QPPA helped your learning most, and in what way." 


\section{RESULTS AND DISCUSSION}

After tallies on the negative statements on the confidence scale were reversed, it was found that an average of $73.7 \%$ participants felt "agree" or "strongly agee" to statements on the scale. For instance, 10 participants marked "strongly agree" and 38 marked "agree" to the statement- "QPPA helped to promote my domain knowledge." Data analyzed on "Students' Confidence Toward QPPA's Potentials in Promoting Cognitive Ability" with one-group $t$-tests, using 3 as the expected mean, yielded that all were statistically significant (refer to Table 1 for details).

Table 1. Frequencies, T- and P-Values of 'Students' Confidence Toward QPPA's Potentials in Promoting Cognitive Ability"

I think ... $1^{*} \quad 2^{*} \quad 3^{*} \quad 4^{*} \quad 5^{*} T$-value $P$-value

1. QPPA helped to promote my domain knowledge.

$\begin{array}{lllllll}0 & 0 & 4 & 38 & 10 & 15.75 & .000\end{array}$

2. QPPA had a facilitating effect for content comprehension.

0

(20)

3. If I can use QPPA to support my learning throughout the semester, I am confident that my capability in the specific subject area will improve.

$\begin{array}{lllllll}0 & 0 & 7 & 21 & 24 & 13.55 & .000\end{array}$

4. QPPA made it harder for me to learn the subject matter.

$\begin{array}{lllllll}10 & 24 & 14 & 4 & 2 & 4.68 & .000\end{array}$

5. Using QPPA helped me understand the subject matter better.

6. Interacting with QPPA made me lose my confidence in learning and mastering the content of the instructional materials.

$5 \quad 18$

17

11

$2.13 \quad .020$

7. My experience in using QPPA made me feel that learning the subject matter is easier.

$\begin{array}{lllllll}0 & 1 & 16 & 25 & 10 & 8.12 & .000\end{array}$

*1 = Strongly Disagree; 2 = Disagree; 3 = No Opinion; 4 = Agree; 5 = Strongly Agree. 
Data on the usefulness of QPPA further showed that a considerably high percentage of participants supported the functions contained in QPPA as being facilitative for their own learning. For example, $86.5 \%$ agreed that questionposing activity was promotive to student learning, while $92.3 \%$ and $90.4 \%$ agreed that peer assessment and drill-and-practice, respectively, helped learning (Table 2). Though comparatively fewer respondents agreed that question-viewing activity assisted their learning $(61.5 \%)$, in-depth interviews revealed that it was mainly due to the fact that currently the system required one Edu-dollar usage fee per question. To increase QPPA's intrinsic motivational value to users, instead of requiring one Edu-dollar usage fee per question viewing, Edu-dollars in terms of average time spent for different learning activity (i.e., question-posing, peer assessment, question-viewing) was used as the basis for Edu-dollars reward accumulation. Furthermore, more than $70 \%$ of the respondents agreed that various auxiliary features in QPPA (i.e., Edu-dollars, statistics summary, online ranking lists) were effective and beneficial to student learning (see Table 2 for reference). Finally, more than $60 \%$ surveyed rated the design of QPPA learning environment as user-friendly and easy to surf within (see Table 3 for details).

Overall, students rated favorably on the system's interface design and potentials in promoting their cognitive capability in the content domain. Student written responses to the open-ended question at the end of the questionnaire further gave insights as to how the learning process supported in the system was viewed

Table 2. Frequencies of Students' Perceptions Toward the Usefulness of QPPA's Features for Learning

\begin{tabular}{llllll}
\hline $\begin{array}{l}\text { I think ... supported in QPPA was effective } \\
\text { and beneficial for my learning. }\end{array}$ & $1^{*}$ & $2^{*}$ & $4^{*}$ & $5^{*}$ \\
\hline 1. Question-posing activity & 0 & 1 & 6 & 30 & 15 \\
2. Peer assessment activity & 0 & 0 & 4 & 32 & 16 \\
3. Question-viewing activity & 0 & 0 & 20 & 25 & 7 \\
4. Drill-and-practice activity & 0 & 0 & 5 & 32 & 15 \\
5. Online ranking lists & 0 & 1 & 11 & 26 & 14 \\
6. Edu-dollars & 0 & 3 & 8 & 30 & 11 \\
7. Statistics summaries on individual performance & 0 & 0 & 14 & 24 & 14 \\
8. Statistics summaries on class average performance & 1 & 1 & 9 & 28 & 13 \\
\hline
\end{tabular}

*1 = Strongly Disagree; 2 = Disagree; 3 = No Opinion; 4 = Agree; 5 = Strongly Agree. 
Table 3. Frequencies of Students' Perceptions Toward the Usability of QPPA's Design

\begin{tabular}{llllll}
\hline I think ... is & $1^{*}$ & $2^{*}$ & $3^{*}$ & $4^{*}$ & $5^{*}$ \\
\hline 1. The log-on procedures of QPPA & 0 & 0 & 2 & 33 & 17 \\
2. The operating procedures of QPPA & 0 & 1 & 3 & 27 & 21 \\
3. Question-posing activity & 0 & 5 & 12 & 22 & 13 \\
4. Peer assesment activity & 0 & 1 & 6 & 29 & 16 \\
5. Drill-and-practice activity & 0 & 4 & 10 & 22 & 16 \\
6. Edu-dollars accumulation & 2 & 5 & 13 & 20 & 12 \\
\hline
\end{tabular}

*1 = Very Difficult; 2 = Somewhat Difficult; 3 = No Opinion; 4 = Easy; 5 = Very Easy.

by students. Constant comparative method suggested by Lincoln and Guba for qualitative data analysis was employed on the 58 entries obtained [29]. Comments like the following were among the common themes, which helped to provide descriptive evidence for the system's facilitative effect for student learning- "Constructing multiple-choice questions helped me understand the subject matter better"; "generating plausible alternatives for multiple-choice questions helped me concentrate more"; "peer assessment gave me a chance to see how others constructed question stems and options"; "peer assessment of the questions posed by peers gave me the opportunity to see others' flaws in reasoning, which helped my learning immensely"; "through carefully analyzing question-stems and plausible options peer assessment and question-viewing helped my learning"; "posing questions for others to answer gives me a sense of achievement"; etc.

In addition to quantitative and qualitative data gained from the questionnaire, observations during the classrooms further showed that students were focused, fervent, and enthusiastic throughout the study. Activities like gazing through textbooks, comparing different sources of references about concepts, asking for clarifications for a specific term, inquiring about different ways to frame a question, arguing over options for their plausibility with other peers, rushing toward the computer lab before the class starts, logging on the system after classes, etc., were norm behaviors exhibited during the activity. These kinds of engaging behaviors actualized what constructivists and cognitive psychologists suggested as signs of active and meaningful learning.

Considering that current questions contained in drill-and-practice and testing learning systems were mostly from instructors and textbook publishers, which 
are compatible with traditional transmission/reception models of teaching and learning [16], systems allowing students to pose, assess, and view questions should be emphasized to acknowledge contemporary constructivist paradigm of teaching and learning. By doing so, a more constructive learning atmosphere may be cultivated where students construct and re-construct their own interpretations of the world of information around them, which should be facilitative for their own understanding and cognitive development.

\section{CONCLUSIONS}

With the advent of networking and multimedia technologies, the emphasis on technology-based education of all kinds for the support of student learning has been the focus of contemporary education. In the present study, in light of constructivism and cognitive psychology a networked learning system enabling students to pose questions, which were further evaluated and viewed by peers, was designed. A study examining the system's potentials for cognitive enhancement was conducted with 52 sixth graders. Via playing the roles of question-posers, assessors, viewers, revisers, and answers at different points during the process, students seemed to actively engage in the learning process by constructing and re-constructing their own interpretations of the world of information around them, which, as viewed by participants, was facilitative for understanding and cognitive development.

Potential topics for future studies were offered. First, during the process of question-posing, peer assessment, and question-viewing, deep-information processes are frequently observed. Despite meta-cognitivists and information processing theorists suggesting that such processes would be promotive to student cognitive and meta-cognitive growth [30-32], few empirical studies were available. Future studies geared toward substantiating the cognitive spin-off effects of question-posing, peer assessment, and question-viewing will be an area worth exploring.

In addition, though most students ardently participated in the activity, two below-average students had an especially hard time engaging in question-posing activity. The potentials of pairing up students with different achievement levels during question-posing activity may be one topic that would yield insightful guidelines for instructors.

Third, currently peer review was designed as a quality control mechanism. As described previously, only after each question is evaluated by at least five peers, and with at least $2 / 3$ of these rating the question as acceptable, can the question be transferred to the formal item bank database. The suitability of such mechanism in terms of validity and reliability may need further field-testing and calibration to ensure that all tests including in the formal item bank database and eventually JOYCE are psychometrically sound. 
Finally, while focusing on the learning activity at hand, the implementer found that students frequently checked online ranking lists to see if they made it to any of the lists. It seems that ranking lists acted as a powerful motivating mechanism to keep students on the task. Currently six ranking lists with the top five best performers in each respective category are provided in the system. In the future, different types of ranking lists can be provided and, from research's perspective, the interacting effects of student satisfaction and motivation toward the learning experience and the number of ranking lists provided as well as the number of best performers permissible in different ranking lists can be examined to aid system designers in making informative decisions on this aspect.

\section{ACKNOWLEDGMENTS}

Thanks are extended to Yeh, Chia-Chung for his assistance in revising the system and Chung-Chi Hung for collecting the data for the study.

\section{REFERENCES}

1. S. M. Alessi and S. R. Trollip, Multimedia for Learning: Methods and Development (3rd Edition), Allyn and Bacon, Boston, Massachusetts, 2001.

2. R. Heinich, M. Molenda, J. D. Russell, and S. E. Smaldino, Instructional Media and Technologies for Learning (7th Edition), Prentice Hall Merrill Education, Upper Saddle River, New Jersey, 2002.

3. T. C. Hsu and S. F. Sadock, Computer-Assisted Test Construction: The State of the Art, ERIC: ED 272515, 1985.

4. M. Laurier, What We Can Do with Computerized Adaptive Testing . . . and What We Cannot Do, paper presented at the Annual Meeting of the Regional Language Center Seminar, Singapore, April 9-12, 1990.

5. D. R. Eignor, Guidelines for Computerized-Adaptive Test Development and Use in Education, Journal of Educational Measurement, 34, pp. 97-100, 1997.

6. E. Bicanich, S. B. Hardwicke, T. Slivinski, and J. T. Kapes, Internet-Based Testing: A Vision or Reality? Journal of Technological Horizons in Education, September 1997.

7. M. W. Goldberg, Using a Web-Based Course Authoring Tool to Develop Sophisticated Web-Based Courses, in Web-Based Instruction, B. H. Khan (ed.), Educational Technology, Englewood Cliffs, New Jersey, 1997.

8. D. Kerven, E. Ambos, and E. Frost, Interactive Web-Based Quizzes Using the Review Automated Generation Systems (RAGS), International Journal of Educational Telecommunications, 4:1, pp. 31-44, 1998.

9. B. H. Khan, Web-Based Instruction (WBI): What Is It and Why Is It? in Web-Based Instruction, B. H. Khan (ed.), Educational Technology Publications, Englewood Cliffs, New Jersey, pp. 5-18, 1997.

10. G. Kearsley, Introduction, Online Education: Learning and Teaching in Cyberspace, Wadsworth, Belmont, California, pp. 1-12, 2001. 
11. J. Zhang, D. H. Cooley, and Y. Ni, NetTest: An Integrated Web-Based Test Tool, International Journal of Educational Telecommunications, 7:1, pp. 33-35, 2001.

12. L. J. Chang, J. C. Yang, F. Y. Yu, and T. W. Chan, Development and Evaluation of Multiple Competitive Activities in a Synchronous Question-Answering Game System, Journal of Innovations in Education and Teaching International, 40:1, pp. 16-26, 2003.

13. F. Y. Yu, L. J. Chang, Y. H. Liu, and T. W. Chan, Learning Preferences towards Computerized Competitive Modes, Journal of Computer-Assisted Learning, 18:3, pp. 341-350, 2002.

14. G.-F. Chiou, Beliefs and Computer-Based Learning, Educational Technology, 35:3, pp. 48-52, 1995.

15. M. J. Hannafin, K. M. Hannafin, S. M. Land, and K. Oliver, Grounded Practice and the Design of Constructivist Learning Environments, Educational Technology Research and Development, 45:3, pp. 101-117, 1997.

16. E. A. Silver, On Mathematical Problem Posing, For the Learning of Mathematics, 14:1, pp. 19-28, 1994.

17. C. Reigeluth, Instructional-Design Theories and Models, Lawrence Erlbaum Associates, Hillsdale, New Jersey, 1983.

18. M. C. Wittrock, The Cognitive Movement in Instruction, Educational Psychology, 13, pp. $15-29,1978$.

19. E. Balajthy, Using Student-Constructed Questions to Encourage Active Reading, Journal of Reading, 27:5, pp. 408-411, 1984.

20. C. Brindley and S. Scoffield, Peer Assessment in Undergraduate Programmes, Teaching in Higher Education, 3:1, pp. 79-90, 1998.

21. L. D. English, Children's Problem Posing within Formal and Informal Context, Journal for Research in Mathematics Education, 29:1, pp. 83-106, 1998.

22. S. J. Hanrahan and G. Isaacs, Assessing Self- and Peer-Assessment: The Students' Views, Higher Education Research \& Development, 20:1, pp. 53-70, 2001.

23. S. S. Leung and R. X. Wu, Problem Posing with Middle Grades Mathematics: Two Real Classroom Examples, Mathematics Teaching in the Middle School, National Council of Teachers of Mathematics, Reston, Virginia, 1999.

24. E. Z. F. Liu, C. H. Chiu, S. S. J. Lin, and S. M. Yuan, Student Participation in Computer Science Courses via the Networked Peer Assessment System (NetPeas), Advanced Research in Computer and Communications in Education, 2, pp. 774-777, 1999.

25. H. C. Purchase, Learning about Interface Design through Peer Assessment, Assessment \& Evaluation in Higher Education, 25:4, pp. 341-352, 2000.

26. M. Searby and T. Ewers, An Evaluation of the Use of Peer Assessment in Higher Education: A Case Study in the School of Music, Kingston University, Assessment \& Evaluation in Higher Education, 22:4, pp. 371-384, 1997.

27. K. E. Topping and S. E. Ehly, Peer-Assisted Learning, Journal of Educational and Psychological Consultation, 12:2, pp. 113-132, 2001.

28. M. H. Hung, The Effects of Sub-Titles and Captions on Foreign Language Learning, unpublished Master's thesis, Graduate Institute of Education, National Cheng-Kung University, 2001.

29. Y. S. Lincoln and E. G. Guba, Naturalistic Inquiry, Sage Publications, Beverly Hills, 1985. 


\section{6 / YU, LIU AND CHAN}

30. S. M. Napell, Using Questions to Enhance Classroom Learning, Education, 99:2, pp. 188-197, 1978.

31. R. L. Reed, Questioning and Its Implications for Educational Research, ERIC DO. ED: $164374,1978$.

32. W. P. Robinson, Educational Curiosity and Questioning, ERIC DO. ED 094850, 1974.

Direct reprint requests to:

Fu-Yun Yu

Graduate Institute of Education

National Cheng-Kung University

No. 1, Ta-Hseuh Rd.

Tainan, Taiwan, R.O.C. 701

e-mail: fuyun@mail.ncku.edu.tw 
Copyright of Journal of Educational Technology Systems is the property of Baywood Publishing Company, Inc. and its content may not be copied or emailed to multiple sites or posted to a listserv without the copyright holder's express written permission. However, users may print, download, or email articles for individual use. 